\title{
Biogas and Dimethyl Ether are Providing Water, Fertilizer for an Intelligent Smart Soil
}

\author{
Johann Gruber Schmidt* \\ Technical University Vienna, Austria \\ Received: 制June 15, 2018; Published: 眥July 03, 2018 \\ *Corresponding author: Johann Gruber Schmidt, Technical University Vienna, Austria
}

\section{Short Communication}

Biogas is well known in agriculture and food industry. In Austria we realized a project Hagenbrunn [1] nearby Vienna/ Austria, a biogas plant running on waste food and liquid biogenic waste. The electric power output is given with $1320 \mathrm{~kW}$ ele, the thermal heat generation is given with $1800 \mathrm{~kW}$ thermal heat realized with warm water $\left(95^{\circ} \mathrm{C} / 60^{\circ} \mathrm{C}\right)$, the substrate feed is given with $25,000 \mathrm{t} /$ year, and the digestate coming out of the biogas plant is $35000 t / y e a r$. The biogas generation of the different substrates, like waste food, grass, potatoes (e.g.) is done by measurements, testing and calculation and leads to the biogas generated by fermentation in a range of $700 \mathrm{Nm}^{3} / \mathrm{h}$ up to $800 \mathrm{Nm}^{3} / \mathrm{h}$, with a methane concentration of $50 \%$ up to $65 \%$. The biogas plant Hagenbrunn [1] has a deep influence on the way of irrigation, the way of fertilizing in agriculture and vine culture. The biogas plant Hagenbrunn [1] has a deep influence on the regional jobs, the regional companies, it is acting like a knot and center of competence and initiating a lot of spin offs. The main advantage of the biogas plant is using biogenic waste as input substrate and therefore the communities are glad to have a sink using and converting waste food and liquid biogenic waste to biogas. Biogas from the plant is only an intermediate step. In the first realization step biogas is converted to electricity and heat.

In the next realization step the biogas plant was enlarged with a preparation of the digestate, to distilled water, solid particles and fertilizer, and the gasification of biogenic solids and the conversion of syngas from gasification of the biogenic solids, biogas from the biogas plant, and the waste biogas from the closed digestate tank to generate syngas with steam gasification and producing dimethyl ether. Dimethyl ether is stored in two tanks, with a volume of 30,000liters, and a filling station of mobile movable bottles substituting LPG by Dimethyl ether. Heavy tank trucks are transporting Dimethyl ether to the clients. The production of dimethyl ether in Hagenbrunn [1] is given by $800 \mathrm{~L} / \mathrm{h}$, using 10,000t/ year biogenic solids, $80,000 \mathrm{~m}^{3} / \mathrm{h}$ waste gas $\left(\mathrm{CH}_{4}=5 \%, \mathrm{CO}_{2}=95 \%\right)$ from the digestate tank of the Biogas plant, and $400 \mathrm{~m}^{3} / \mathrm{h}$ biogas $\left(\mathrm{CH}_{4}=50 \%, \mathrm{CO}_{2}=50 \%\right)$ from the biogas plant. Additional heat from the CHP engine is used for drying the solids biomass to a moisture lower than $10 \%$. The electric power needed for the production of dimethyl ether, for the drying process, and the generation of fertilizer and water from digestate is produced by the gasification plant. Now the Biogas plant now can convert liquid biogenic waste and solid biogenic waste and can so take over the waste from the region.

\section{Biogas plant}

A biogas plant consists of substrate storage for at least a six months operation (Figure 1), buffering the different mass flow of substrate during the operation of a year. Additional we have a preparation of the substrates increasing the surface, and to prepare for the fermentation in the digester. Because of the wet process we have to mix the substrate with the fluid circulating in the plant between the digester by a pump (often called central pump). For the biogas process we have to understand biogas processes operating on waste, like food waste, manure, and substrates like corn, maize, beet. The process ends with a digester and the with a storage of the digestate (end product of the fermentation process). In input substrate is defined by the gas production of the fresh mass (measured, tested or calculated by formulas (Brick, Schumann)), the anaerobic fermentation process, and at the end to get back the digestate. The biogas resulting form the digester is collected and burned in a CHP engine to produce electricity and heat. But nobody needs electricity and heat, additional the earn of electricity and heat is very small, the economic situation becomes very bad. To get a feeling about the dimension, area, input, output, efficiency we have: electric power output: $\mathrm{P}=500 \mathrm{~kW}$ ele, input feed: 17,500 $\mathrm{t} /$ year wet fresh substrate, output $15500 \mathrm{t} / \mathrm{a}$ digestate, generated heat $\mathrm{Q}(\mathrm{th})=700 \mathrm{~kW}$ th, generated biogas $300 \mathrm{Nm}^{3} / \mathrm{h}\left(50 \% \mathrm{CH}_{4}, 50 \%\right.$ $\mathrm{CO}_{2}$ ), the agricultural area needed for supporting the biogas plant 
with waste is at least needed with 200 ha area. The area needed for

soil needed. Additional the digestate resting in a tank is producing the biogas plant itself is about 1 ha. With this correlation we plan and design the water consumption, water storage, fertilizer and

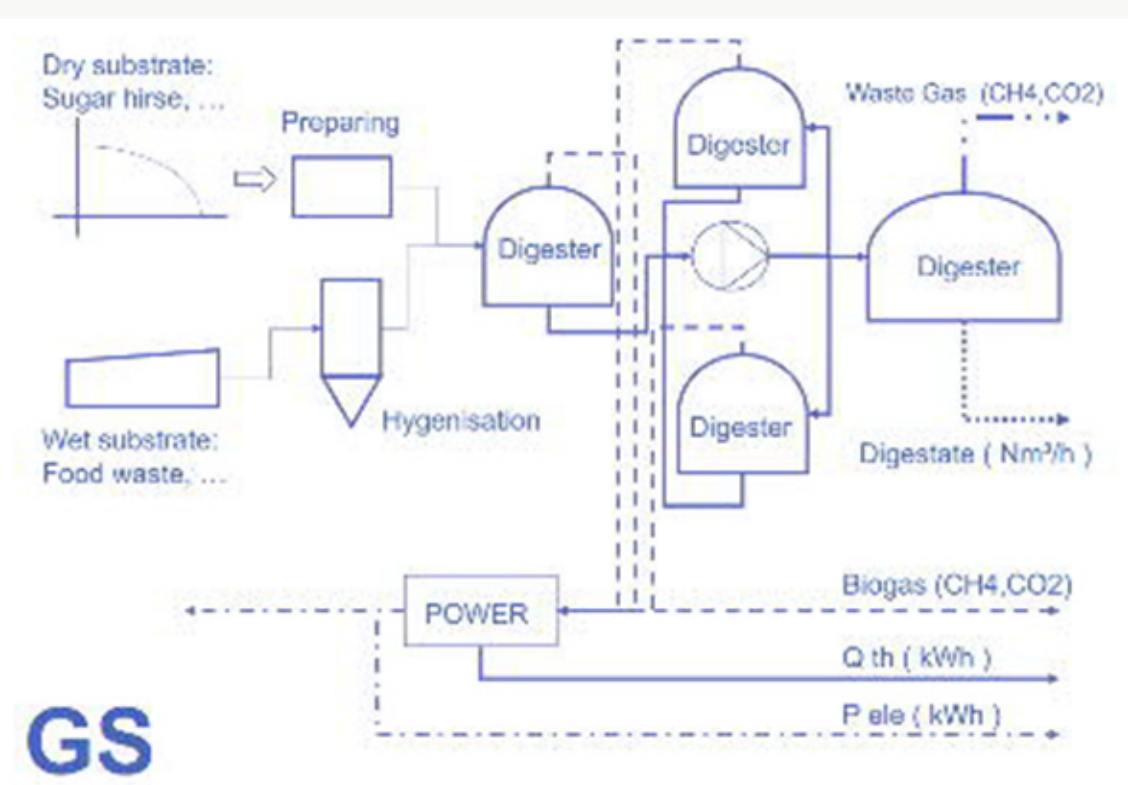

Figure 1: Biogas Plant.

\section{Dimethyl ether}

Dimethyl ether is well known. It is the simplest ether consisting of two carbon atoms, one oxygen atom and six hydrogen atom, molar mass MZ 46g/mol [2]. It is certificated by ISO 16 681: 2013 by the IDA. At a pressure of 6 bar Dimethyl ether is in liquid phase at an environment temperature of $25^{\circ} \mathrm{C}$ [2] The simplest ether is synthetic and can produced with two pathways: the production in two steps in the first step over the intermediate product methanol (methanol synthesis) $\mathrm{CO}+2 \mathrm{H}_{2} \rightarrow \mathrm{CH}_{3} \mathrm{OH}+\mathrm{Q}(-225 \mathrm{~kJ} / \mathrm{mol})$ and in the second step over dehydration (water removal) $2 \mathrm{CH}_{3} \mathrm{OH} \rightarrow \mathrm{CH}_{3}$ $\mathrm{OCH}_{3}+\mathrm{H}_{2} \mathrm{O}+\mathrm{Q}(-15 \mathrm{~kJ} / \mathrm{mol})$, or in the direct synthesis in one step $3 \mathrm{CO}+3 \mathrm{H}_{2} \rightarrow \mathrm{CH}_{3} \mathrm{OCH}_{3}+\mathrm{CO}_{2}+\mathrm{Q}(-254 \mathrm{~kJ} / \mathrm{mol})$. The difference between both chemical processes is the energy (heat generated and needed) the resulting mass flows generated by the processes. The caloric heat value of dimethyl ether is given caloric combustion enthalpy $\mathrm{Hc}=1460 \mathrm{~kJ} / \mathrm{mol}$ [2], the formation standard formation enthalpy $\mathrm{Hf}=184 \mathrm{~kJ} / \mathrm{mol}$ [2]. The combustion of dimethyl ether in diesel engines leads to nearly no soot, dust, a reduction of carbon monoxide and nitrogen oxide [3].
GS

\section{BIOGAS PLANT}

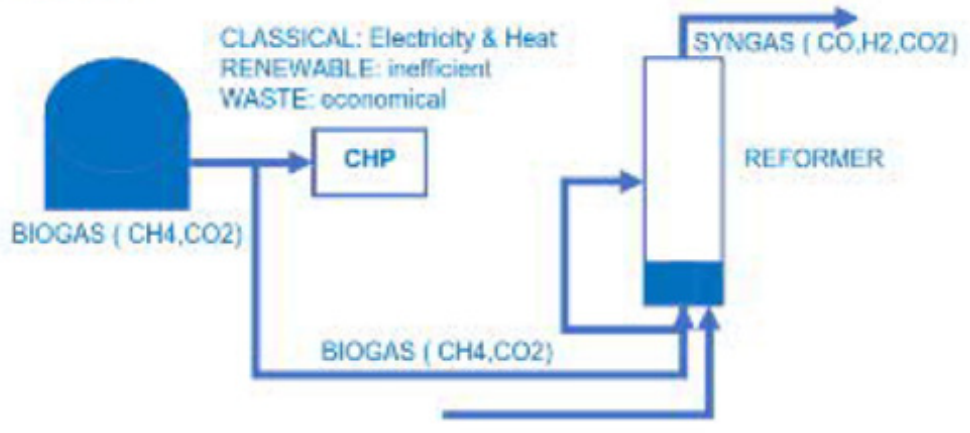

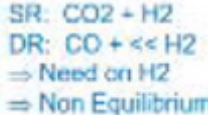

DR: $\mathrm{CO}+<<\mathrm{H} 2$

$\Rightarrow$ Need cn $\mathrm{H2}$

Figure 2: Biogas Plant and reformer for syngas. 


\section{Biogas to dimethyl ether}

The convertion of biogas to dimethyl ether can be done in two pathways. One pathway is steam reforming of biogas, which leads to a snygas consisting of carbon monoxide and hydrogen and carbon dioxide (SR=steam reforming reaction) (Figure 2). $\mathrm{CH}_{4}+\mathrm{H}_{2} \mathrm{O} \longrightarrow \mathrm{CO}+3 \mathrm{H}_{2}+\mathrm{Q} \quad(+316 \mathrm{~kJ} / \mathrm{mol})$, or in combination with more steam (WGS $=$ Water gas shift reaction) to carbon dioxide and hydrogen $\mathrm{CH}_{4}+2 \mathrm{H}_{2} \mathrm{O} \longrightarrow \mathrm{CO}_{2}+4 \mathrm{H}_{2}+\mathrm{Q}(+161 \mathrm{~kJ} / \mathrm{mol})$ (Figure $3)$. The second pathway is dry reforming of biogas to carbon monoxide and hydrogen $\mathrm{CH}_{4}+\mathrm{CO}_{2} \longrightarrow 2 \mathrm{CO}+2 \mathrm{H}_{2}+\mathrm{Q}(+251 \mathrm{~kJ} / \mathrm{mol})$ [1]. In processes we need heat, generated from the biogas itself
$\mathrm{CH}_{4}+2 \mathrm{O}_{2} \rightarrow \mathrm{CO}_{2}+\mathrm{H}_{2} \mathrm{O}+\mathrm{Q}(-574 \mathrm{~kJ} / \mathrm{mol})$. The gained syngas is then converted to dimethyl ether. The standard process of convertion of syngas to dimethyl ether consist of a gas compression up to 50 bar till to 100 bar, the reduction of carbon dioxide by cooling down the syngas and condensation of carbon dioxide and storing in a tank, the convertion of the syngas to methanol in one reactor, with recycling of the unconverted syngas and condensation of water and methanol mixture [1]. The condensate mixture is separated with distillation into process water and methanol. The methanol is dehydrated to dimethyl ether and the condensate mixture of dimethylether, water is separated with distillation into process water and dimethyl ether. $2 \mathrm{CH}_{3} \mathrm{OH} \rightarrow \mathrm{CH}_{3} \mathrm{OCH}_{3}+\mathrm{H}_{2} \mathrm{O}+\mathrm{Q}(-15 \mathrm{~kJ} / \mathrm{mol})$ [1].

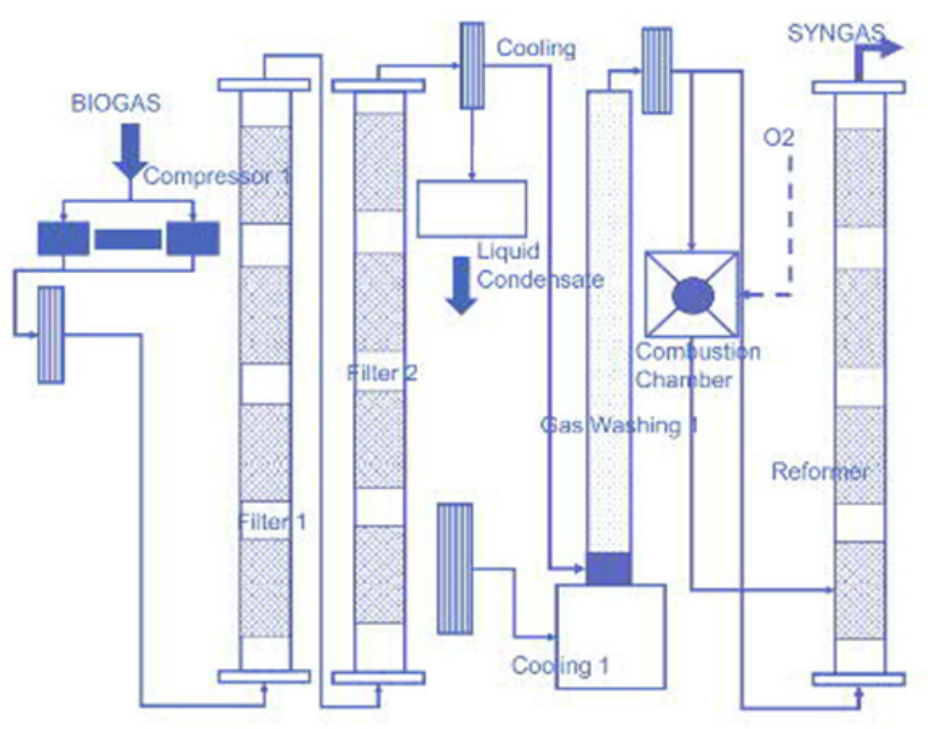

Figure 2: Biogas Cleaning and syngas reformer.

\section{Combination of processes}

\section{GS BIOMASS TRAISMAUER I}

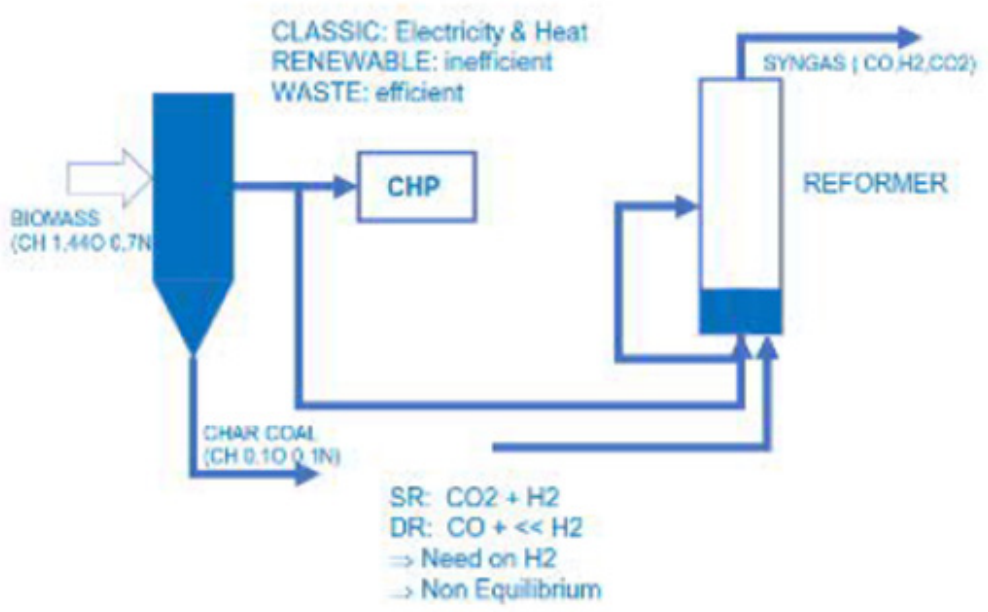

Figure 4: Gasification plant and syngas reformer. 
Figure 4 to increase the efficiency of a biogas plant the biogas plant is combined with a gasification plant. Such as gasification plant is realized in the project Traismauer in Austria [4]. The gasification plant converts solid biomass to weak gas mainly consisting of $\mathrm{CO}=20 \%, \mathrm{H}_{2}=23 \%, \mathrm{CH} 4=1 \%, \mathrm{CxHy}=3 \%$, Rest $\mathrm{CO}_{2^{\prime}}$ with a heat caloric value $\mathrm{Hu} \sim 2.2 \mathrm{~kJ} / \mathrm{m}^{3}, \operatorname{tar}<5 \mathrm{mg} / \mathrm{Nm}^{3}$, dust < $5 \mathrm{mg} / \mathrm{Nm}^{3}$ which is used to generate with a CHP engine (combined heat process) electricity and heat. Syngas from the gasification and char coal are converted with steam gasification to syngas with a steam reformer operating at nearly environment pressure and a temperature of $800{ }^{\circ} \mathrm{C}$ up to $1000{ }^{\circ} \mathrm{C}$. The syngas composition is given by $\mathrm{CO}=30 \%, \mathrm{H}_{2}=30 \%, \mathrm{CH}_{4}=1 \%, \mathrm{CxHy}=3 \%$ and the rest is $\mathrm{CO}_{2}$, with a heat caloric value $\mathrm{Hu} \sim 2.8 \mathrm{~kJ} / \mathrm{m}^{3}$. In the project Hagenbrunn [1] we combined the biogas plant with a gasification plant as done in the project Traismauer [2]. We call this gasification the bottom cycle producing weak gas with a caloric heat value $\mathrm{Hu} \sim 2.2 \mathrm{kWh} /$ $\mathrm{Nm}^{3}$ (Figure 5). To generate the needed heat for steam (hv=2560kJ/ $\mathrm{kg}$ ) and to superheat steam up to $800{ }^{\circ} \mathrm{C}$ till $1000{ }^{\circ} \mathrm{C}$, we need a combustion chamber, in which the weak gas of the gasification plant is burned with oxygen to carbon dioxide and steam. Additional we use the biogas from the biogas plant in the steam gasifier and fine milled biomass mixed with char coal from the biomass gasifier. $\mathrm{CH}_{4}+\mathrm{H}_{2} \mathrm{O} \longrightarrow \mathrm{CO}+3 \mathrm{H}_{2}+\mathrm{Q}(+206 \mathrm{~kJ} / \mathrm{mol}), \mathrm{C}+\mathrm{H}_{2} \mathrm{O} \rightarrow \mathrm{CO}+\mathrm{H}_{2}+\mathrm{Q}(+145 \mathrm{~kJ} /$ $\mathrm{mol})$. A very interesting property is given by using carbon dioxide in steam gasification $\mathrm{C}+\mathrm{CO} 2 \rightarrow 2 \mathrm{CO}+\mathrm{Q}(+180 \mathrm{~kJ} / \mathrm{mol})$. The syngas has now a composition by $\mathrm{CO}=40 \%, \mathrm{H} 2=40 \%, \mathrm{CH} 4=1 \%, \mathrm{CxHy}=3 \%$ and the rest is $\mathrm{CO}_{2}$ with a heat caloric value $\mathrm{Hu} \sim 3.5 \mathrm{~kJ} / \mathrm{m}^{3}$, tar $<0.5 \mathrm{mg} /$ $\mathrm{Nm}^{3}$, dust $<1 \mathrm{mg} / \mathrm{Nm}^{3}$. This syngas is converted to dimethyl ether. From the CHP plant we generate the electric energy and heat needed in the enlarged biogas plant to run all processes.

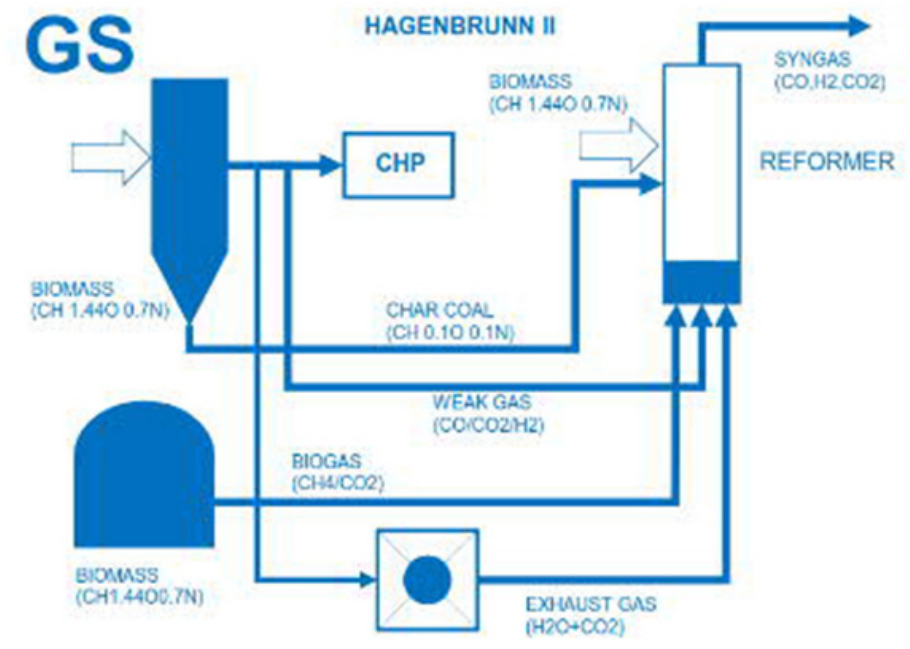

Figure 5: Biogas Plant combined with a gasification plant and syngas reformer.

\section{Intelligent smart soil}

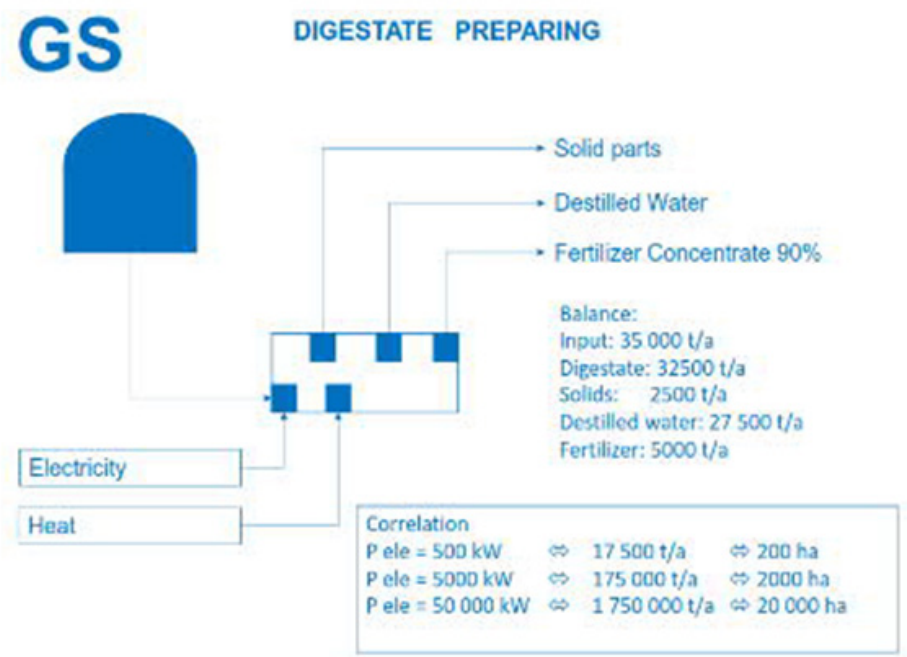

Figure 6: Biogas Plant and up scaling digestate conversion. 
One of the main and central (Figure 6) parts of the project Hagenbrunn [1] is the conversion of the digestate into solids, water and fertilizer. The disadvantage for a classical Biogas plant, we need electric power and heat. In the project Hagenbrunn [1] we need $\mathrm{P}=150 \mathrm{~kW}$ ele and $\mathrm{Q}=800 \mathrm{~kW}$ thermal power for digestate 35,000 $\mathrm{t} /$ year. This is not efficient for a classical Biogas plant. Therefore we need additional heat and electric power and we need a high valued product like dimethyl ether to reach an energetic and financial efficiency to be worth for investment (Figure 7). First let have a look on the digestate from the Biogas Plant [1]. The digestate consist of metalöls like Cadmium, Chrome, Copper, Lead, Nickel, Mercury, Zinc, Arsenic, Cobalt, resulting from food itself. Under solid parts we understand organic particles and fibers coming out of the fermentation process, consisting of lignin, cellulose, hemi cellulose and poly sugars (called the TS=dry substance). Then we have the fertilizer parts like Ammonia, Phosphates, Calcium oxide, Potassium oxide, Magnesium oxide, Natrium oxide, Sulfates, Chlorides, Nitrates. The preparation process for the digestate is divided into two steps: the mechanical step, and the refining step of the liquid fertilizer.

\begin{tabular}{|c|c|c|c|c|c|c|}
\hline TS & $\%$ & 2.79 & 0.0279 & $\mathrm{~kg}$ & 27900 & $m g$ \\
\hline Biøl & $\mathrm{mg} / \mathrm{kg} \mathrm{TS}$ & 4.7 & $1.3113 E-07$ & $\mathrm{~kg}$ & 0.13113 & $\mathrm{mg}$ \\
\hline Cadmium & $\mathrm{mg} / \mathrm{kg}$ TS & 1 & $2.79 \mathrm{E}-08$ & $\mathrm{~kg}$ & 0.0279 & $\mathrm{mg}$ \\
\hline Chrom & $\mathrm{mg} / \mathrm{kg}$ TS & 9 & $2.511 E-07$ & $\mathrm{~kg}$ & 0.2511 & $\mathrm{mg}$ \\
\hline Kupfer & $\mathrm{mg} / \mathrm{kg}$ TS & 36 & $1.0044 \mathrm{E}-06$ & $\mathrm{~kg}$ & 1.0044 & $\mathrm{mg}$ \\
\hline Nickel & $\mathrm{mg} / \mathrm{kg}$ TS & 12 & $3.348 \mathrm{E}-07$ & $\mathrm{~kg}$ & 0.3348 & $m g$ \\
\hline Quecksilber & $\mathrm{mg} / \mathrm{kg}$ TS & 0.01 & $2.79 \mathrm{E}-10$ & $\mathrm{~kg}$ & 0.000279 & $\mathrm{mg}$ \\
\hline Zink & $\mathrm{mg} / \mathrm{kg} \mathrm{TS}$ & 177 & $4.9383 \mathrm{E}-06$ & $\mathrm{~kg}$ & 4.9383 & $\mathrm{mg}$ \\
\hline Arsen & $\mathrm{mg} / \mathrm{kg}$ TS & 1.6 & $4.464 \mathrm{E}-08$ & $\mathrm{~kg}$ & 0.04464 & $\mathrm{mg}$ \\
\hline Kobalt & $\mathrm{mg} / \mathrm{kg}$ TS & 2.9 & $8.091 \mathrm{E}-08$ & $\mathrm{~kg}$ & 0.08091 & $\mathrm{mg}$ \\
\hline & & & & & & \\
\hline TOC & $\mathrm{mg} / \mathrm{kg}$ TS & 328600 & 0.00916794 & $\mathrm{~kg}$ & 9167.94 & $\mathrm{mg}$ \\
\hline & & & & & & \\
\hline Stickstoff & $\%$ TS & 18.7 & 0.0052173 & $\mathrm{~kg}$ & 5217.3 & $\mathrm{mg}$ \\
\hline Phosphor & $\%$ TS & 2 & 0.000558 & $\mathrm{~kg}$ & 558 & $\mathrm{mg}$ \\
\hline $\mathrm{CaO}$ & $\%$ TS & 4.8 & 0.0013392 & $\mathrm{~kg}$ & 1339.2 & $\mathrm{mg}$ \\
\hline K2O & $\%$ TS & 5.64 & 0.00157356 & $\mathrm{~kg}$ & 1573.56 & $\mathrm{mg}$ \\
\hline MgO & $\%$ TS & 0.63 & 0.00017577 & $\mathrm{~kg}$ & 175.77 & $\mathrm{mg}$ \\
\hline $\mathrm{Na} 2 \mathrm{O}$ & $\%$ TS & 8.75 & 0.00244125 & $\mathrm{~kg}$ & 2441.25 & $\mathrm{mg}$ \\
\hline $\mathrm{SO} 4$ & $\%$ TS & 1.62 & 0.00045198 & $\mathrm{~kg}$ & 451,98 & $\mathrm{mg}$ \\
\hline & & & & & & \\
\hline ph Wert & $x$ & 8.17 & & & & \\
\hline Sigma & $\mu S / \mathrm{cm}$ & 40300 & & & & \\
\hline & & & & & & \\
\hline Ammonium & $\mathrm{mgn}$ & 3960 & 0.00396 & $\mathrm{~kg}$ & 3960 & $\mathrm{mg}$ \\
\hline Clonid & $\operatorname{mgn}$ & 2780 & 0.00278 & $\mathrm{~kg}$ & 2780 & $\mathrm{mg}$ \\
\hline Nitrat & $\mathrm{mg} /$ & 0.45 & 0.00000045 & $\mathrm{~kg}$ & 0.45 & $\mathrm{mg}$ \\
\hline Nitrit & $\mathrm{mg} /$ & 0.46 & 0.00000046 & $\mathrm{~kg}$ & 0.46 & $\mathrm{mg}$ \\
\hline Phospaht & $\mathrm{mgn}$ & 56.7 & 0.0000567 & $\mathrm{~kg}$ & 56.7 & $\mathrm{mg}$ \\
\hline Sulfat & $\mathrm{mg} / \mathrm{s}$ & 3.2 & 0.0000032 & $\mathrm{~kg}$ & 3.2 & $\mathrm{mg}$ \\
\hline & & & & & & \\
\hline
\end{tabular}

\begin{tabular}{|l|l|r|r|r|r|r|}
\hline Halogenv. & $\mathrm{mg} / \mathrm{kg}$ TS & 240 & 0.0000048 & $\mathrm{~kg}$ & $4.8 \mathrm{mg}$ \\
\hline POX & $\mathrm{mg} / \mathrm{kg}$ TS & 1.6 & & $3.2 \mathrm{E}-08 \mathrm{~kg}$ & $0.032 \mathrm{mg}$ \\
\hline AOX & $\mathrm{mg} / \mathrm{kg}$ TS & 720 & & 0.0000144 & $\mathrm{~kg}$ & $14.4 \mathrm{mg}$ \\
\hline LAS & $\mathrm{mg} / \mathrm{kg}$ TS & 120 & & 0.0000024 & $\mathrm{~kg}$ & $2.4 \mathrm{mg}$ \\
\hline Phenol & $\mathrm{mg} / \mathrm{kg}$ TS & 97 & & 0.00000194 & $\mathrm{~kg}$ & 1.94 \\
\hline CSB & $\mathrm{mg} / \mathrm{mg}$ \\
\hline
\end{tabular}

Produkte
\begin{tabular}{|l|r|l|l|}
\hline GR & 36000 & $\mathrm{~m}^{2} / J a h r$ & \\
\hline Feststoff & 1004.4 & UJahr & \\
\hline Festdũnger & 423.25416 & UJahr & \\
\hline Deionat & 25000 & tJahr & $(\mathrm{s}<10 \mu \mathrm{S} / \mathrm{cm})$ \\
\hline
\end{tabular}

Figure 7: Content of dig estate -Biogas Plant [3].

The first step is a mechanical separation of the solids out of the digestate. The digestate consists normally of $90 \%$ water, $3 \%$ up to $5 \%$ solid particles and $5 \%$ fertilizer solved in water. After the mechanical separation done with a sieve separator we use a fine sieve again to prepare the liquid digestate for filtration by membranes. The solid water mixture is like slurry is recycled in a water plant. The filtration process is closed with a membrane process, the ultra filtration stage $(\mathrm{d} \sim 1 \mu \mathrm{m})$ to clear and separate the collides from the digestate. Now we have reached a clear liquid fluid with solved minerals, oxides, carbonates, phosphates and sulfates. This is the first stage of usable for droplet irrigation. The advantage for this first stage: it is easy to reach, the electric power needed is $\mathrm{P} \sim 50 \mathrm{~kW} / \mathrm{Nm}^{3}$ is very small. The disadvantage is we cannot influence the concentration of the solved minerals, oxides, carbonates, phosphates and sulfates itself. The clarified digestate from the first stage can be easily used for droplet irrigation, which saves more than $50 \%$ of water consumption. The needed electricity and energy is gained from the gasification plant and from dimethyl ether, which can be used as fuel for the diesel engine driven pumps transporting the water in the pipe lines on site outside the Biogas plant. So we save energy, we save water consumption and we have the possibility of installation of doplet irrigation. Those parameters are very interesting for investors and communities and companies in agriculture and food and wine industry forced to save costs, 
water and fertilizer. There is no need of continuing the wasting water by inefficient water irrigation and also the costs for synthetic fertilizer can be reduced.

In the second step we take now the liquid fertilizer and separate the water. We use the Nano filtration $(\mathrm{d} \sim 0.01 \mu \mathrm{m})$ to reach a high concentration of the solved minerals, oxides, carbonates, phosphates and sulfates, stored in a tank. Now we are in the position to dilute the high concentrate with water according to the demands of the clients. In the project Hagenbrunn [1] we also developed a step further. We are in close contact with the client and measure the moisture of the soil; we measure minerals, oxides, carbonates, phosphates and sulfates in the soil [3]. Although the biogenic plants, like a vine culture, are intelligent by it and can organize and influence the microbes by chemical substances in the soil, we now can support the plant culture with water, minerals, oxides, carbonates, phosphates and sulfates according to the measurements and the need. What do we understand under need: we measure the quality of the grapes, corn, fruits in the different growing state itself, depending on the temperatures, solar environment, and with this data we are now in the position to close the controlling cycle: the measurement of the actual state of the culture pant, the quality to be reached and the need on water, minerals, fertilizer. This all is realized in a digital process system and visualization for steady local watching and controlling. The realization of this project enables us to get a deep inside look into the structure and behavior of the soil and the growth of the plant and enables us to optimize and to increase the growth efficiency.

\section{Closure}

In the project Hagenbrunn [1] we have shown that a Biogas plant can be enlarged with a gasification [4] to generate electricity and heat, to support the production of dimethyl ether [5] and to prepare and separate the digestate from the Biogas Plant into distilled water and fertilizer [1]. Under these conditions dimethyl ether becomes a smart rural fuel with an impact on transportation, on water supply and consumption in agriculture and food industry and in the consumption of fertilizers. Additional the Biogas Plant is now converting to a center of competence influencing the regional companies and jobs and as a hot spot it is a part of a network. If we now spread of a region Biogas plants with a power of 5MW we cover up an agricultural area of 2000 ha up to 3000 ha. With Biogas Plants in the power range of $5 \mathrm{MW}$ up to $50 \mathrm{MW}$ we can cover up a region of 2,000,000 ha agricultural area. With this network of Biogas Plant as hot spots in the region we can lower the water consumption, we can dramatically increase the production of dimethyl ether as a fossil Diesel substitute and we can reduce the synthetic fertilizer consumption. Additional we increase the jobs in the region and we supply. Biogas Plants costs investment, but the financial investment for private investors is much smaller than the investment of a congress or community in water pipe lines. Over a period of 15 years we develop the region sustainable and as an add on we save the environment. But this is not important for an investor looking for a low risk investment, and for opportunities in future. But the network of Biogas plant is not working against itself; the Biogas Plants are supporting the network, are supporting each other and therefore are stabilizing the infrastructure and environment [6-11].

\section{References}

1. J Gruber-Schmidt (2017) Hagenbrunn - Biogas. Slovakia.

2. (2018) NIST Web Book.

3. (2012) Tier 1 Report, EPA Department.

4. J Gruber Schmidt (2017) Traismauer - Recycling. Hungary.

5. RF Probstein (2012) Synthetic Fuels. Dover Publ.

6. J Gruber Schmidt (2016) Smart rural Fuel. Ossiach, Austria.

7. Ke Liu, et al. (2014) Hydrogen and Syngas. Wiley.

8. Urs von Stockar (2016) Biothermodynamics. Epfel Press, CRC Press.

9. Maria Duca (2015) Plant Physiology. Springer Publ.

10. HG Jones (2011) Plants and Microclimate. CUP Publ.

11. Alan R Hamsley (2004) From Plant Physiology to Ecosystems. Elesvier Publ.

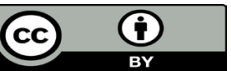

This work is licensed under Creative Commons Attribution 4.0 License

To Submit Your Article Click Here: Submit Article
DOI: 10.32474/CIACR.2018.03.000164

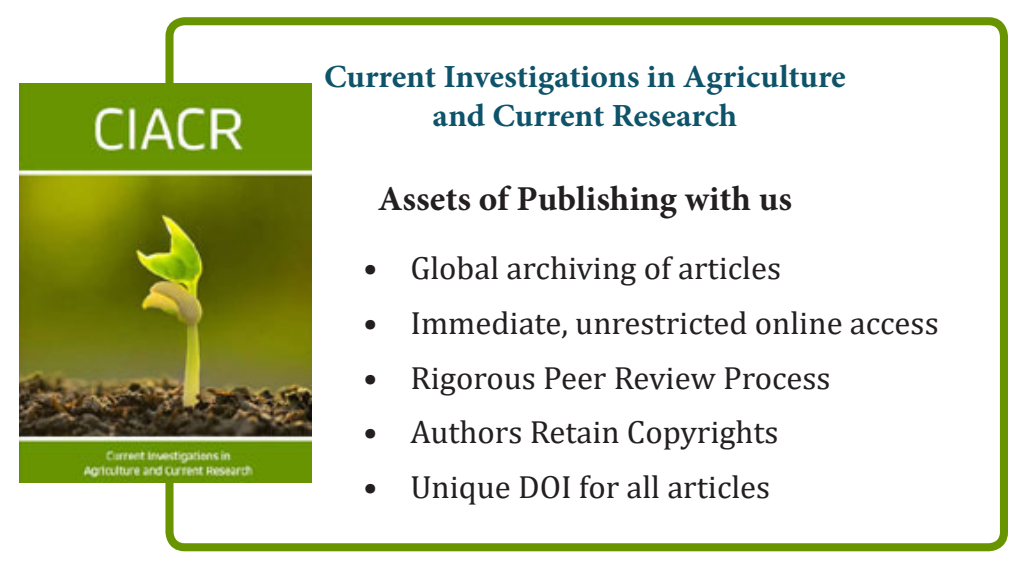

